\section{PROCESSING AND DIGITALIZATION OF VALUES OF GEOMETRIC TOLERANCES}

\author{
MATEJ HRABCAK, LUBA BICEJOVA, SLAVKO PAVLENKO \\ Department of Design and Monitoring Technical Systems, \\ Faculty of Manufacturing Technologies with a seat in Presov, \\ Technical University of Kosice, Presov, Slovak republic
}

DOI: 10.17973/MMSJ.2019_12_2019027

luba.bicejova@tuke.sk

Achievement of desired service life, of correct and reliable function as well as meeting demands regarding replacement of engineering products requires observance of exact dimensions of functional areas as well as accuracy of geometrical shape, direction, reciprocal position of areas and of other elements of components. Tolerance of shape, of direction, of position and of flapping is commonly referred to as geometric tolerance. The paper describes the created application which allows the user simple, fast and unlimited search for value of geometric tolerance.

KEYWORDS

geometric tolerances, digitalization, application

\section{INTRODUCTION}

Geometric tolerances represent an inseparable part of engineering industry. Therefore, processing and digitalization of values of geometric tolerances appear to be useful for a design engineer or for a technologist. Processing of geometric tolerances can be performed by means of several methods. The first method includes web interface in case of which all data of the area of values of individual tolerances are processed and on the basis of inputs, i.e. according to entered parameters, the web browser displays respective geometric tolerance of the desired dimension. In practice it means that lengthy search for geometric tolerance value in a dictionary of mechanical engineering would no longer be inevitable. The other option is creation of application which could be downloaded into an appliance with the android operating system. It would be based on the same principle as web site yet no Internet connection would be necessary.

\section{GEOMETRIC TOLERANCES}

Achievement of desired service life, of correct and reliable function as well as meeting demands regarding replacement of engineering products requires observance of exact dimensions of functional areas as well as of accuracy of geometrical shape, direction, reciprocal position of areas and of other elements of components [Krenický 2017].

\subsection{Fundamental terms and definitions}

Tolerance of shape, of direction, of position and of flapping is commonly referred to as geometric tolerance.

Fundamental terms of geometric tolerance are the following: element, deviation, tolerance.

- Element (geometric element) - point, line or surface.
- Integral (geometric) element - surface or line along the surface.

- Derived (geometric) element - centre, centre line or centre surface derived from a single or several integral surfaces.

- Dimension element - geometric shape defined by length or by angular dimension.

- Nominal integral element - theoretically accurate (nominal) integral element as defined by technical drawing.

- Nominal derived element - centre, axis or centre plane derived from a single or several rated (nominal) integral surfaces.

- Actual surface of workpiece - set of elements which physically exist and separate a workpiece from the surrounding environment [Kočiško 2012].

- Actual integral (geometric) element - integral part of an element of the actual surface of a workpiece.

- Extracted integral element - approximated representation of the actual element achieved by extraction of the final number of points of the actual element. Extraction is performed as per agreement.

- $\quad$ Extracted derived element - centre, centre line or centre surface derived from a single or several extracted integral elements.

- Associated integral element - integral element of regular (perfect) shape matched to the extracted integral element as per agreement.

- Associated derived element - centre or centre surface derived from a single or several associated integral surfaces [Pavlenko 2017a,b].

- Deviation - the term refers to general description of geometry of actual areas and profiles and to standard assessment of results of measurement of actual areas, profiles and other elements.

- Tolerance - general definition refers to the highest permitted numeric value of considered deviations which determine characteristic dimension of plane or spatial tolerance fields [Bičejová 2017a,b].

- Tolerance area - geometric tolerance applied in case of an element defines tolerance area within which all points of the assessed element must be located [Maščenik 2017a,b]. According to the type of element and its quota method the tolerance area can be limited as follows:

- by two equidistant lines,

- by a cylinder,

- by two centred circles,

- by two concentric cylinders,

- by two parallel planes,

- by spherical space.

To assure explicitness of each geometric tolerance, the definition of tolerance area must be explicit as well. In general, the method of tolerated element check depends on definition of tolerance area [Šmeringaiová 2018a].

\subsection{Classification of geometric tolerancing}

Pursuant to STN ISO 1101 standard the types of geometric tolerances are marked by a graphic symbol on the drawing (Table 1 ) and by additional symbol (Table 2 ). 
Table 1: Classification of geometric tolerance pursuant to ISO 1101 standard - graphic symbols

\begin{tabular}{|c|c|c|c|}
\hline Tolerance & Characteristics & Symbol & $\begin{array}{c}\text { Base } \\
\text { requirement }\end{array}$ \\
\hline \multirow{6}{*}{$\begin{array}{l}\text { Shape } \\
\text { tolerance }\end{array}$} & Straightness & - & no \\
\hline & Planeness & $\square$ & no \\
\hline & Roundness & & no \\
\hline & Cylindricity & $D V$ & no \\
\hline & Profile shape of arbitrary line & 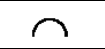 & no \\
\hline & $\begin{array}{l}\text { Profile shape of arbitrary } \\
\text { surface }\end{array}$ & $\triangle$ & no \\
\hline \multirow{5}{*}{$\begin{array}{l}\text { Orientation } \\
\text { tolerance }\end{array}$} & Parallelism & $/ 1$ & yes \\
\hline & Perpendicularity & $\perp$ & yes \\
\hline & Angle bevel & $\angle$ & yes \\
\hline & Profile shape of arbitrary line & $\curvearrowleft$ & yes \\
\hline & $\begin{array}{l}\text { Profile shape of arbitrary } \\
\text { surface }\end{array}$ & $\bigcirc$ & yes \\
\hline \multirow{6}{*}{$\begin{array}{l}\text { Position } \\
\text { tolerance }\end{array}$} & Location & $\phi$ & yes or no \\
\hline & Concentricity (for centres) & (O) & yes \\
\hline & Alignment (for axes) & (O) & yes \\
\hline & Symmetry & $\overline{-}$ & yes \\
\hline & Profile shape of arbitrary line & $\curvearrowleft$ & yes \\
\hline & $\begin{array}{l}\text { Profile shape of arbitrary } \\
\text { surface }\end{array}$ & $\bigcirc$ & yes \\
\hline \multirow{2}{*}{$\begin{array}{l}\text { Flapping } \\
\text { tolerance }\end{array}$} & Circular flapping & 1 & yes \\
\hline & Overall flapping & $\mathbb{1}$ & yes \\
\hline
\end{tabular}

Table 2: Additional symbols of geometric tolerance

\begin{tabular}{|c|c|c|}
\hline Characteristics & Symbol & Reference \\
\hline Symbol of tolerated element & & ISO 1101 standard \\
\hline Symbol of basic element & $\left.\right|_{\text {मी }} ^{A}$ मी & ISO 5459 standard \\
\hline Symbol of partial base & $\frac{\phi 2}{A 1}$ & ISO 5459 standard \\
\hline Theoretically accurate dimension & 50 & ISO 5458 standard \\
\hline Shifted tolerancing zone & & $\begin{array}{c}\text { ISO } 10578 \\
\text { standard }\end{array}$ \\
\hline $\begin{array}{c}\text { Requirement regarding maximal } \\
\text { material }\end{array}$ & & ISO 2692 standard \\
\hline $\begin{array}{c}\text { Requirement regarding minimal } \\
\text { material }\end{array}$ & & ISO 2692 standard \\
\hline Reciprocity requirement & (R) & ISO2692 standard \\
\hline $\begin{array}{l}\text { Condition of free state } \\
\text { (ductile components ) }\end{array}$ & & $\begin{array}{l}\text { ISO } 10579 \\
\text { standard }\end{array}$ \\
\hline \multicolumn{3}{|l|}{ Around the outline (profile) } \\
\hline $\begin{array}{l}\text { Requirement regarding wrapping } \\
\text { area }\end{array}$ & & ISO 8015 standard \\
\hline Common zone & CZ & \\
\hline Low diameter & LD & \\
\hline Maximal diameter & MD & \\
\hline Mean diameter (pitch) & PD & \\
\hline Line element & LE & \\
\hline Non-convex & NC & \\
\hline
\end{tabular}

Arbitrary cross-section

$\mathrm{ACS}$

2.3. Methods of prescribing the geometric tolerances in the technical drawings

\subsubsection{Tolerance frame}

Required tolerances are recorded in tolerance frames divided into two more parts which in left-to-right direction contain the following:

- symbol of tolerated geometric characteristics,

- numerical value of tolerance expressed in $\mathrm{mm}$,

- in case of necessity a letter or letters referring to basic shaping element or base system are added as well (fig. 1).

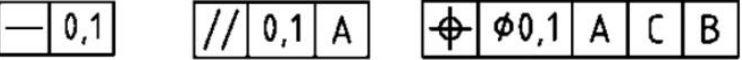

Figure 1: Basic shapes of tolerance frames

If specific shape of tolerance field must be determined, the shape is prescribed by numerical value of tolerance extended (fig. $2 a, b$ ) by the following:

- symbol $\varnothing$ in case of circular or cylindrical tolerance field,

- $\quad$ symbol $\varsigma \varnothing$ in case of spherical tolerance field.

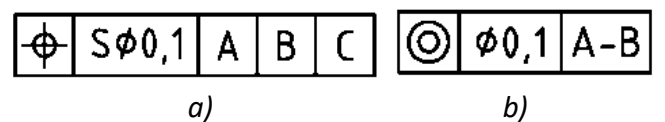

Figure 2: Symbols of specific shapes of tolerance fields

\subsection{Bases for geometric tolerances}

Bases and systems of bases for geometric tolerance are used as foundation for formation of geometric relations among the particular elements. Quality of particular basic elements and of spare basic elements must correspond to functional requirements, STN ISO 5459 standard defines basic terms:

- Base - theoretically accurate geometric element (e.g. symmetry axis, plane, straight line) which the tolerated element relates to. Bases can compose of a single or of several basic elements of the component.

- System of bases - a group with two or several bases.

- Basic element - actual element of the component (e.g. edge, area or hole) used to determine the position of base.

The base can compose of a single or several elements:

- Base composing of a single element. If the base composes of a single element only, it shall be marked by one letter in the third field of a tolerance frame. For instance, in figure $3 a$ axis of symmetry represents the base.

- Common base composing of two elements. If common base composes of two elements, it shall be marked by two letters divided by dash in the third field of tolerance frame. Figure $3 b$ shows an example of the base represented by common axis of two cylinders by means of which the shaft is located in bearings.

- System of bases composing of two or several elements. In case of direction tolerances only one or two bases are usually used. Relation of location often requires basic system composing of three reciprocally perpendicular planes. In such cases it is necessary to determine their order and on the basis of priorities primary, secondary and tertiary base musr be determined. The order of bases influences achieved results. The letters referring to bases are recorded into the third and into the following fields 
of tolerance frames according to the bases (figure $3 c$-bases are represented by two supporting areas and axis of symmetry) [Šmeringaiová 2018b].

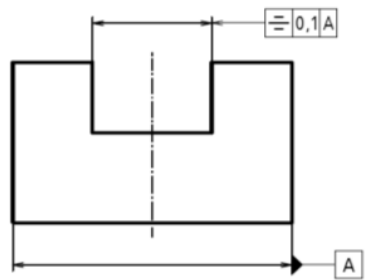

a)

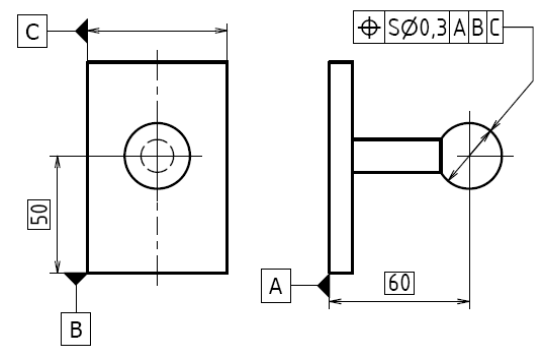

c)

Figure 3: Marking of bases

- Partial bases. Due to particular production reasons it is suitable to opt for smaller areas- partial bases instead of large area - base in case of which it is not possible to achieve desired accuracy. Especially clamping surfaces or storage places in production and measurement are recommended to be selected as partial bases. Partial base can be the following:

- $\quad$ point - marked by a cross (fig. $4 a$ ),

- $\quad$ segment - marked by two crosses connected with a thin continuous line (fig. $4 b$ ),

- circular or square area - marked by a thin dot-dash line with two dots and cross-hatching (fig. $4 c$ ).

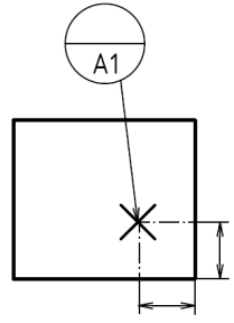

a)

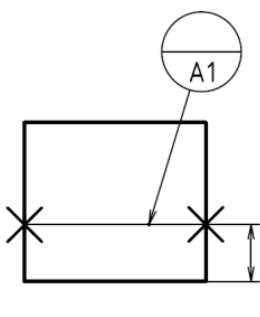

b)

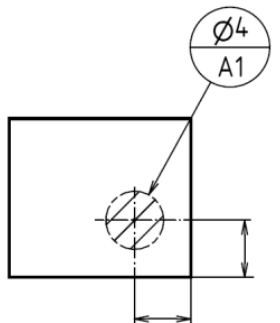

c)
Figure 4: Marking of partial bases

\section{DIGITALIZATION OF VALUES OF GEOMETRIC TOLERANCES}

Digitalization of values of geometric tolerances refers to transformation of text, of values or of diverse data from a book format into electronic one. Once the application has been installed into device the application shall be displayed on the desktop (fig.5). The result is the application created in a mobile device which can be activated and used without being connected to the Internet in the device with the Android platform (fig.6) in case of which the application user shall select a geometric tolerance, a tolerance level and a nominal dimension. Consequently, the tolerance value shall be displayed.

\subsection{Applied Software, Complements in Application Creation for OS Android}

The following softwares were used to create the application for OS Android:

\subsubsection{Node.js}

It refers to auxiliary software serving for writing of the internet application with high scaling, especially of web servers. Node.js uses program language of JavaScript. It is applied in case of processing of JavaScript out of browser. The part of Node.js is a packed manager npm (node.js manager) serving for a simple distribution of programs being programmed in node.js. Apache Cordova is also available as a package within the frame of npm.

\subsubsection{Apache Cordova}

It refers to popular framework for development of mobile application which allows creation of applications only with the use of web technologies such as HTML5, CSS3 and JavaScript instead of applying native languages for Java in case of Android. Advantage of Cordova rests in the fact that with the use of the same code it is possible to develop applications for diverse platforms such as Android, iOS, Windows phone, Blackberry, etc.

\subsubsection{Android $s d k$}

The software tools are used by Apache Cordova for creation of applications for smartphones with OS Android.

\subsubsection{Java sdk}

Java SE Development Kit is a developing environment for creation of applications and component with the use of programming language Java. Since natively API is for the Android applications programmed in programming language Java, Android sdk uses right the Java skd.

\subsubsection{Microsoft Excel}

Excel represents table software by the company of Microsoft which was used as software for creation of .csv files. The Csv files are inevitable for processing of tables with the values of geometric tolerances. The Csv (Comma separated values) - is a format needed for processing of selected values of geometric tolerances with assurance of legibility and consequent use in web application.

\subsection{Created Application}

Figure 5 shows the created application in case of which a respective geometric tolerance, tolerance level and shaft diameter can be selected. Consequently, the figure 6 is displayed (activated application) in case of which the user can see the deviation of the selected geometric tolerance as well as its detailed description [Maščenik 2017].

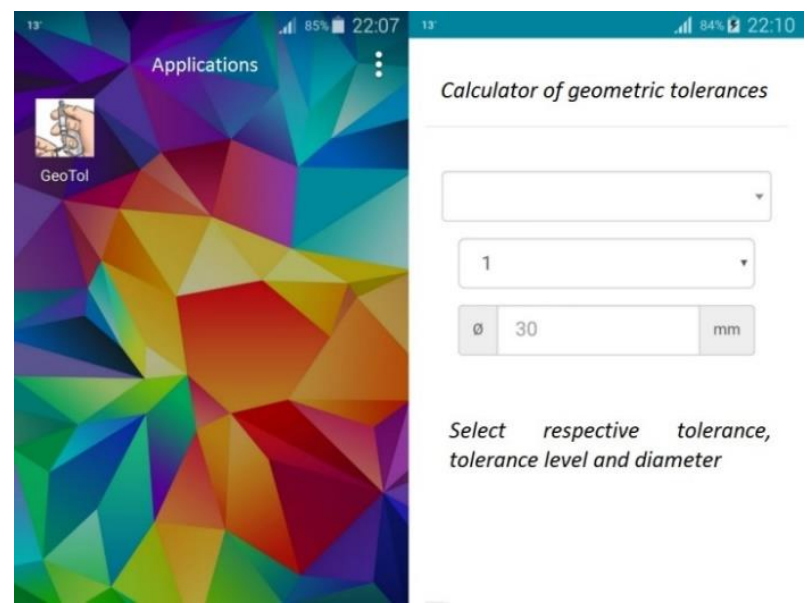

Figure 5: Application installed in the device 


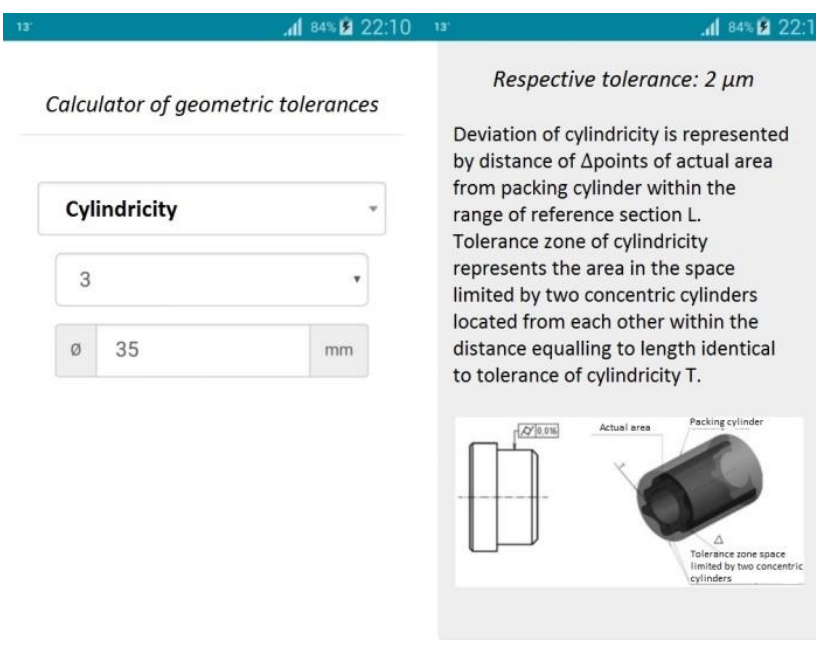

Figure 6: Activated application

\section{CONCLUSION}

The vision of the paper was to point out to the possibility of conversion of values of geometric tolerances into digital form which would thus simplify work with geometric tolerances. Creation of application for device with the operating system Android is beneficial not only for a design engineer or a technologist but also for technically oriented secondary schools and universities. Of course, the application solves the issue only partially. Complementing the information and data from dictionary of mechanical engineering regarding values of dimensions of, for instance, tolerance fields of shafts and holes, threads, bearings, screws, matrices, pins, bolts, washers, tight splines, etc. would result in solution of complex issue concerning not only geometric tolerances. Processing of data from dictionary of mechanical engineering would lead to acceleration of search as well as to simplification and increase of the productivity rate.

\section{Acknowledgement}

This article has been prepared within the project KEGA 051TUKE$4 / 2018$.

\section{REFERENCES}

[Bičejová 2017a] Bičejová, Ĺ. Experimental measurements of shape deviations of machine components. MM Science Journal, 2017, No. November, pp. 1891-1894. ISSN 1803-1269.

[Bičejová 2017b] Bičejová, Ĺ. Design of a program for check and calculation of belt gears. MM Science Journal, 2017, No. November, pp. 1887-1890. ISSN 1803-1269.

[Kočiško 2012] Kočiško, M., Matija, R., Vojtko, I. Aspect theoretical of machining. In: Proceedings of 11th International Scientific Conference NWMT 2012: New Ways in Manufacturing Technologies. Prešov, 21th-23th June 2012, Slovakia. Košice: TUKE, 2012, pp. 166-173. ISBN 978-80-553-0908-8.

[Krenický 2017] Krenický, T., Olejárová, Š. Manufacturing technologies: materials, operation and application. Zurich: Trans Tech Publications, 2017, 155 p. ISBN 978-3-0357-1196-7.

[Maščenik 2017a] Maščenik, J. Monitoring of parameters directly influencing performance transfer by belt gear. MM Science Journal, 2017, No. December, pp. 1959-1962. ISSN 18031269.

[Maščenik 2017b] Maščenik, J. Design of a material cutting device with option of length adjustment of wooden cutting substance. MM Science Journal, 2017, No. December, pp. 19191923. ISSN 1803-1269.

[Pavlenko 2017a] Pavlenko, S. Design of a program for calculation of forcing spring stiffness. MM Science Journal, 2017, No. December, pp. 1924-1928. ISSN 1803-1269.

[Pavlenko 2017b] Pavlenko, S. Design and check of the mechanical components by the PC application. MM Science Journal, 2017, No. December, pp. 1914-1918. ISSN 1803-1269. [Šmeringaiová 2018a] Šmeringaiová, A., Wittner, M. Parametric Modeling as Efficient Way of Designing. MM Science Journal, 2018, No. December, pp. 2701-2705. ISSN 1803-1269.

[Šmeringaiová 2018b] Šmeringaiová, A., Pavlenko, S., Wittner, M., Šmeringai, P. Digital Manufacturing in Small Companies Environment. In: MMS 2018: 3rd EAI International Conference on Management of Manufacturing Systems. Gent, Belgium, 2018; European Alliance for Innovation, pp. 1-8. ISBN 978-163190-167-6, ISSN 2593-7642.

\section{CONTACTS}

M.Sc. Matej Hrabcak, M.Sc. Luba Bicejova, PhD., Prof. M.Sc. Slavko Pavlenko, PhD.

Department of Design and Monitoring Technical Systems, Faculty of Manufacturing Technologies with a seat in Presov, Technical University of Kosice, Presov, Slovak republic

Bayerova 1, Presov, 080 01, Slovak Republic

+421 51772 6321, +421 51772 6312,+421 51772 6456, matej.hrabcak@tuke.sk, luba.bicejova@tuke.sk, slavko.pavlenko@tuke.sk, www.tuke.sk 